\title{
A COMPARISON OF THE AYRES AND THORNDIKE HANDW'RITING SCALES.
}

\author{
RUDOLF PINTNER, \\ Ohio State Unversity.
}

I. Introduction. The purpose of this paper is to estimate the relative accuracy of judgments of handwriting when graded by the Ayres and Thorndike scales, respectively. Now that there are two handwriting scales, the question naturally arises as to which of the two is more useful in the ordinary routine work of grading samples of handwriting. The more the knowledge of educational psychology permeates our school work, and the more our teachers realize the necessity for objective standards of measurement, the more widespread will become the use of all these objective measuring rods, such as handwriting, composition and spelling scales. And the use of such objective scales will stimulate the production of still more. It seems well to the miter, however, that we should be continually testing the scales themselves, so that ultimately the fittest may survive.

What do we mean by the fittest in respect to any such scale? Obviously, the one that will accomplish best the purpose for which it has been designed, and this purpose in the present case I take to be the ease and accuracy with which the scale can be used by the majority of intelligent observers. $A$ scale must be adapted to the use of many observers. That it can be applied with great accuracy by this or that particular individual is no test of its reliability. It must give fairly accurate results with any intelligent individual, and that scale will be the most reliable that shows the least deviation in the judgments of many different individuals. This is obviously of importance if our handwriting scales are to come into gencral use in our scbools, if our superintendents and principals are to make use of them as objective standards of measure. ment for the handwriting of whole classes, or schools, or even school systems. Our problem then reduces itself to this: Given 
the two scales, the Ayres and the Thorndike, which of the two will show the least amount of deviation in the ratings of the same samples by a number of individuals? Or, in more general terms, Which scale shows the greatest amount of agreement in the rating of handwriting by many different individuals?

The composition of the scale has directly nothing to do with this problem. For the practical application of the scale it is immaterial whether the one has been based upon legibility only and the other upon legibility plus aesthetic factors. Both scales represent grades of goodness or badness in handwriting, and the teacher in comparing a definite sample of handwriting with the steps on the scale merely tries to place her sample next to the step which it appears to resemble most. As a matter of fact, in framing the Ayres scale ${ }^{1}$ legibility alone was taken into consideration. No doubt legibility is by far the most important factor in any handwriting. Whether our gen. eral judgment of a definite piece of handwriting is or can be hased solely upon legibility is a different question. The ultimate test of a scale framed in such a manner will have to rest upon its reliability in artual practice. The Thorndike scale," on the other hand, is based upon other factors besides legibility. The qualities of beauty, character, ease, etc., were also taken into account.

11. Grading the Samples. In the present study twentyfour samples of handwriting were graded on both scales by thirty-three observers. Most of these latter were students of a class in educational psychology; some had had experience in actual teaching, and a few of the observers were teachers in the grades. The writer himself was one of the observers. The two scales had been demonstrated before the class; their nature and composition had been made clear, and their aim had been fully explained. The twenty-four samples used in the experiment were chosen out of about 300 samples written by the children of an ordinary grade school. These were all written under conditions as uniform as possible, i. e.,

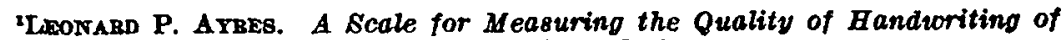
School Children No, 113. Russell Sage Foundation.

'Edward L Tuorndre. Handhoriting. Teachers College, Columbia Unlversity, New York, 1912.
} 
the children wrote for five minutes any selection of poetry or prose that they had committed perfectly to memory. Samples were secured from all of the eight grades. Bad, good and indifferent samples, according to the opinion of the writer, were chosen to make up the twenty-four samples used by the thirty-three observers. The observers were told to grade the twenty-four samples on each of the scales-first on one of the scales and then on the other. No comparison was allowed between their grading on the one scale and their grading on the other. They were told not to allow their judgments on the first scale to prejudice their judgments on the second, and, as a matter of fact, I do not believe that judging on one scale first would influence to any great extent, if at all, the judg. ments on the succeeding scale. The number of samples was too great to allow any memory of the first set of judgments to carry over to the second set. Sometimes the Ayres scale was used first and sometimes the Thorndike. In grading on the Ayres scale the observers were told that they could make use of intermediate steps not marked on the scale. Thus, if they thought a sample was slightly better than 50 , but not quite as good as 60 , they were told to grade it 55 , and so on with all the other intermediate steps.

Unfortunately, no actual count was kept of the preferences of the different observers in regard to the two scales, but the great majority undoubtedly preferred the Ayres. This, I believe, is entirely due to the general make-up of the scale and to the percentage system employed to mark the different steps. The Thorndike scale is unwieldy to handle, the different steps are not clearly enough marked off from each other and the steps are not numbered in the conventional method of percentages so dear to the heart of the teacher.

It will be seen, therefore, that each of the twenty-four samples of handwriting was graded sixty-six times, thirty-three times on the Ayres and thirty-three times on the Thorndike scale, making a total of 1584 judgments. The grades for each sample were added together and an average grade for each sample for the thirty-three observers was obtained. These averages are given below in Table $\mathrm{I}$. 
TABLE I.

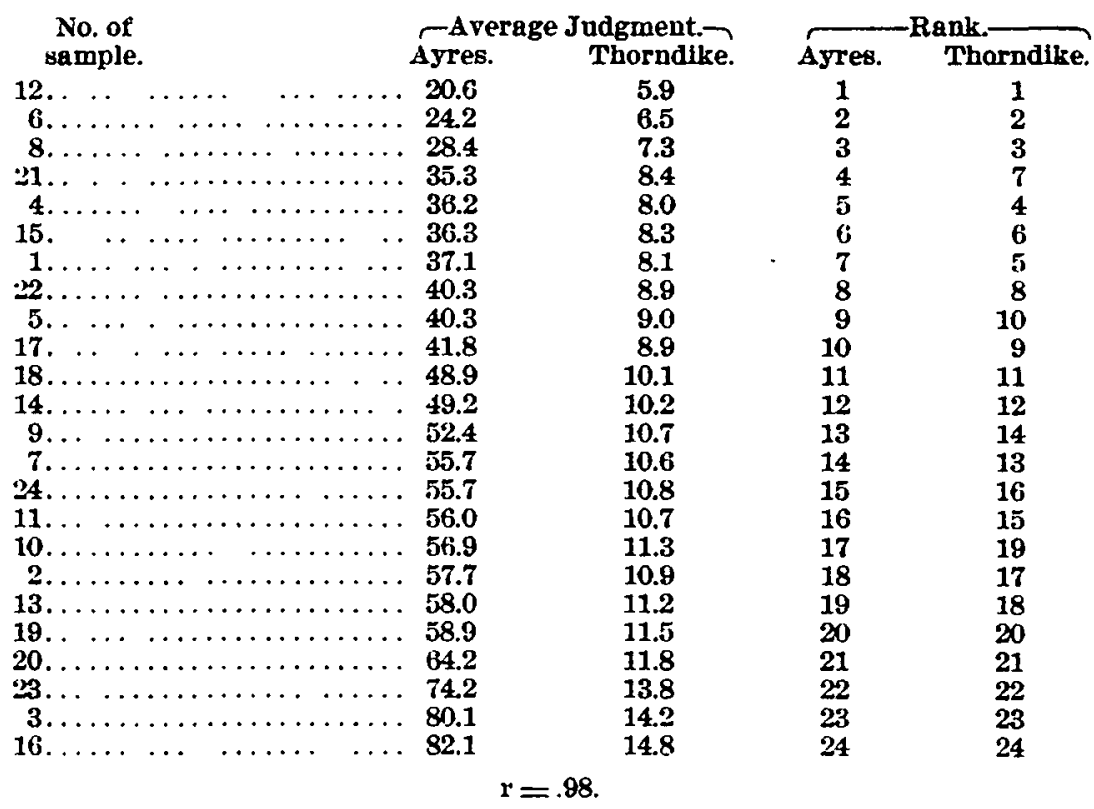

From this table we note first that the samples were fairly representative of good, medium and bad handwriting. Every step on the Ayres scale from 20 to 80 is represented, and similarly with the Thorndike from 5 to 14, with the exception of 12. Further, the rank of each sample on both scales (columns 4 and 5 in Table $I$ from the lowest to the highest is almost identical. The correlation coefficient of the ranks is, in fact, .98. We may interpret this to mean that the observers' standards of gooduess and badness of handwriting have been practically identical in their work with both scales, and also that the steps on both scales correspond, on the whole, very closely with each other.

III. Deviations in Judgment. To calculate the amount of deviation in the judgments of the thirty-three observers, it is obvious that nothing can be done with the actual grades given, because of the difference of the two scales in the methods of denoting the steps. A deviation of two on the Thorndike scale would mean a difference of two whole steps, whereas 
this same deviation on the Ayres would only correspond to one-fifth of a step. The method adopted to make the deviations on each scale directly comparable with each other was to reduce the thirty-three individual gradings of each sample to the basis of fifty. The average of the thirty-three judgments of each individual sample was put equal to fifty, and then the thirty-three judgments were raised to this basis. For example, the average judgment of the thirty-three observers of Sample 1 on the Ayres scale was 37.1. This was put equal to 50, and then each individual judgment was raised

TABLE II.

Sadure 1.-Harry L. Age 8. Second Crade.

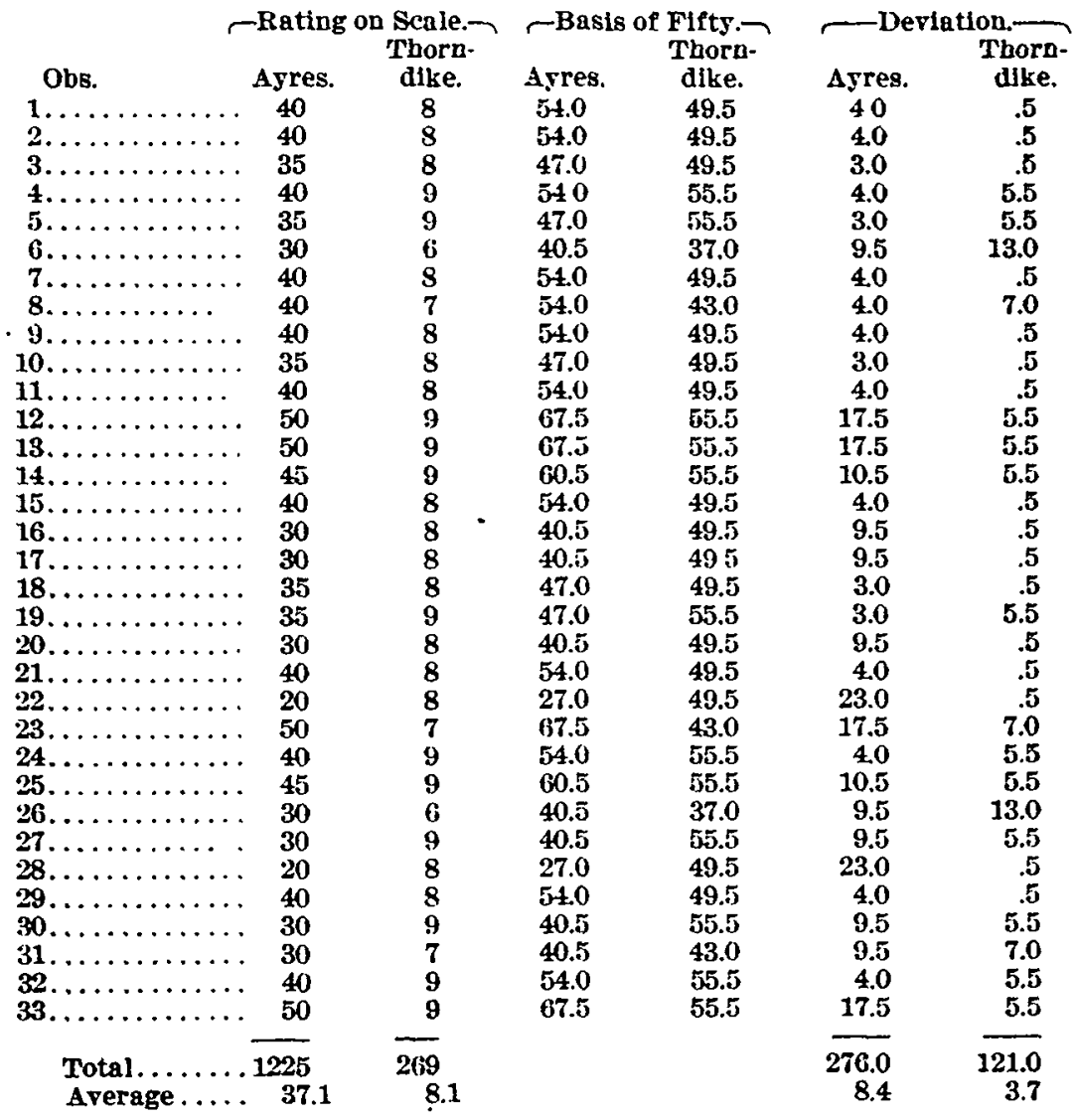


to this basis. In this case Obs. 1's rating of the sample as 40 was now raised to 54 , or 4 above the average; Obs. 6 's rating of the sample as 30 now corresponded to 40.5 , or 9.5 below the average. Similarly for the Thorndike scale. The average for Sample 1 was 8.1. Putting this equal to 50, we have Obs. 1's rating of 8 equal to 49.5 , Obs. 6 's rating of 6 equal to 37.0 , and so on. The thirty-three individual ratings of Sample 1 with the deviations calculated in this manner are shown in Table II.

This table is merely given as an example, for space obviously forbids printing the corresponding figures for each of the other 23 samples. The amount of calculation appears at first sight enormous, but it is extremely simple if a slide rule is used. The Weiss Modified Mannheim Slide Rule ${ }^{3}$ was used in this case. The average is set equal to 50 , and the required numbers are then at once read off around the circle.

TABLE III.

\begin{tabular}{|c|c|c|c|c|c|}
\hline \multirow{3}{*}{$\begin{array}{c}\text { No. of } \\
\text { sample. }\end{array}$} & \multicolumn{2}{|c|}{ Total Derlation. } & \multirow{2}{*}{\multicolumn{2}{|c|}{ Aperage Deviation. }} & \multirow{2}{*}{$\begin{array}{l}\text { matuo. } \\
\text { Tyres to } \\
\text { Thorn- } \\
\text { dike. }\end{array}$} \\
\hline & Bas & of Fifty. & & & \\
\hline & $\begin{array}{l}\text { Ayres. } \\
276.0\end{array}$ & $\begin{array}{c}\text { Thorndilke. } \\
121.0\end{array}$ & $\begin{array}{l}\text { Ayres. } \\
\mathbf{8 . 4}\end{array}$ & $\begin{array}{c}\text { Thorndike. } \\
3.7\end{array}$ & $\begin{array}{r}\text { dike. } \\
.44\end{array}$ \\
\hline & 229.5 & 174.0 & 6.9 & 5.3 & .77 \\
\hline 3. & 120.5 & 186.5 & 3.6 & 5.6 & 1.47 \\
\hline$\ldots$. & 371.5 & 153.5 & 11.2 & 4.6 & .41 \\
\hline ..... & 2666.0 & 137.5 & 8.1 & 4.2 & .52 \\
\hline & 318.0 & 237.0 & 9.6 & 7.2 & .75 \\
\hline & 232.0 & 169.0 & 7.0 & 5.1 & .73 \\
\hline 8. & 340.5 & 246.5 & 10.3 & 7.5 & .73 \\
\hline & 270.0 & 175.5 & 8.2 & 5.3 & .65 \\
\hline 10. & 258.0 & 177.0 & 7.8 & 5.4 & .69 \\
\hline$\ldots \ldots \ldots$ & 278.0 & 131.0 & 8.4 & 4.0 & .48 \\
\hline$\ldots \ldots \ldots$ & 246.5 & 251.5 & 7.5 & 7.6 & 1.01 \\
\hline$\ldots \ldots \ldots$ & 221.5 & 196.5 & 6.7 & 5.9 & .88 \\
\hline$\ldots \ldots \ldots$ & 273.0 & 227.0 & 8.3 & 6.9 & .83 \\
\hline 15. & 245.5 & 152.5 & $\mathbf{7 . 4}$ & 4.6 & .62 \\
\hline 16. & 135.0 & 138.5 & 4.1 & 4.2 & 1.02 \\
\hline 17. & 309.5 & $\mathbf{1 4 9 . 0}$ & 9.4 & 4.5 & .48 \\
\hline 18. & 263.5 & 199.5 & 8.0 & 6.0 & .75 \\
\hline 19. & 258.5 & 196.0 & 7.8 & 5.9 & .76 \\
\hline$\ldots \ldots \ldots$ & 205.0 & 183.0 & 6.2 & 5.5 & .89 \\
\hline$\ldots \ldots \ldots$ & $\mathbf{3 1 3 . 5}$ & 160.5 & 9.5 & 4.9 & .52 \\
\hline$\ldots \ldots \ldots$ & 351.5 & 196.0 & 10.6 & 5.9 & .63 \\
\hline $23 \ldots \ldots \ldots \ldots \ldots$ & 224.5 & 187.5 & 6.8 & 5.7 & .84 \\
\hline $24, \ldots \ldots \ldots \ldots$ & $\mathbf{2 3 8 . 5}$ & 220.0 & 7.2 & 6.7 & .93 \\
\hline $\begin{array}{l}\text { Total } \ldots . . . \\
\text { Average } . .\end{array}$ & 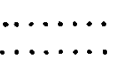 & & $\begin{array}{r}189.0 \\
7.9\end{array}$ & $\begin{array}{r}132.2 \\
5.5\end{array}$ & \\
\hline
\end{tabular}

A. P. Werss. A Modifled Slide Rule and the Index Method in Individual Measurement8. See page 511, this issue. 
For each individual rating we then have a deviation from the average for both scales, and these deviations are furthermore directly comparable. A deviation of 5 on the one scale will be directly comparable to a deviation of 5 or 6 on the other. Table III gives the total deviations from 50 obtained by this method for the twenty-four samples, and also the average deviation of the thirty-three individuals for each sample.

From this table we see that on the whole the deviation on the Ayres scale is considerably greater than on the Thorndike scale. The total average deviation for the Ayres is 189, and for the Thorndike only 132.2. Looking at each individual sample we see that only three show an average deviation on the Thorndike greater than the corresponding deviation on the Ayres. These three are Samples 3, 12 and 16, for which the Thorndike deviations are 5.6, or 2 more than on the Ayres; 7.6 , or .1 more than on the Ayres, and 4.2, or .1 more than on the Ayres, respectively. The difference of .1 is extremely small, and so we have in reality only the case of Sample 3, where the average deviation on the Thorndike is considerably greater than on the Ayres, namely, 2 points. In all the other cases the deviation on the Ayres is greater than on the Thorndike, and in some cases the difference is considerable. This can be easily seen by inspecting the last column of Table MI, where the ratios of the deviations on the Thorndike to those on the Ayres are given. The greatest difference is in Sample 4 , which shows a ratio of .41 and a difference in the average deviation of 6.6 points. The averages of these columns of average deviations are, for the Thorndike, 5.5 points, and for the Ayres, 7.9, which shows a difference of 2.4 points in favor of the Thorndike scale-a difference which is by no means small when it is remembered that each of these final averages is based upon 792 judgments.

We may therefore sum up this section of the investigation by saying that with the great majority of the twenty-four samples of handwriting, the Thorndike scale gives the most uniform results, inasmuch as the deviation among different individuals is less than on the Ayres scale. With only three samples was the amount of deviation in favor of the Ayres scale, and in only one case was the amount of any consequence. 
IV. Deviations of Observers. We might next raise the question as to whether the same superiority of the Thorndike scale holds good with each particular individual. Are the deviations of each particular individual from the average judgment of all the individuals less for the Thorndike than for the Ayres scale? Of course, we know already that as a whole this is true, but it will be more convincing if we can show that this is a general tendency among all the thirts-thret individuals, or at least among most of them.

TABLE IY.

\begin{tabular}{|c|c|c|c|c|c|}
\hline \multirow[b]{2}{*}{ Obs. } & \multicolumn{2}{|c|}{$\begin{array}{l}\text { Total Deviation. } \\
\text { for } 24 \text { Samples. }\end{array}$} & \multicolumn{2}{|c|}{ Average Deviation. } & \multirow{2}{*}{$\begin{array}{l}\text { Batio. } \\
\text { Ayres to } \\
\text { Thorn- } \\
\text { dike. }\end{array}$} \\
\hline & Ayres. & Thorndike. & Ayres. & Thorndike. & \\
\hline $1 \ldots \ldots \ldots \ldots$ & 177.5 & $12 \% .5$ & 7.4 & 5.2 & $.70^{\circ}$ \\
\hline $2 \ldots \ldots .$. & 230.5 & 130.0 & 9.6 & 5.4 & .56 \\
\hline $3, \ldots \ldots \ldots \ldots$ & 176.0 & 173.0 & 7.3 & 7.2 & .99 \\
\hline $4 \ldots \ldots, \ldots$ & 151.5 & 94.0 & 6.3 & 3.9 & .62 \\
\hline $5 \ldots \ldots \ldots$ & 147.5 & 1455 & 6.1 & 6.1 & 1.00 \\
\hline $6 \ldots \ldots \ldots \ldots$ & 169.0 & 140.0 & 7.0 & 5.8 & .83 \\
\hline $7 \ldots \ldots \ldots \ldots$ & 135.5 & 71.5 & 5.6 & 3.0 & 54 \\
\hline $8, \ldots . \ldots$ & 151.5 & 132.5 & 6.3 & 5.5 & $.8 \pi$ \\
\hline $9 \ldots \ldots \ldots$ & 156.5 & 176.0 & 6.5 & 7.3 & 112 \\
\hline $10 \ldots \ldots \ldots \ldots$ & $184 . \overline{6}$ & 113.5 & 7.7 & 4.7 & .61 \\
\hline $11 \ldots \ldots \ldots, \ldots$ & 139.5 & 104.0 & 5.8 & 4.3 & .74 \\
\hline $12 \ldots \ldots \ldots \ldots$ & 158.5 & 121.0 & 6.6 & 5.0 & .76 \\
\hline $13 \ldots \ldots \ldots \ldots$ & 142.5 & 130.5 & 5.0 & 5.4 & .92 \\
\hline $14 \ldots \ldots \ldots \ldots \ldots$ & 228.0 & 105.5 & 9.5 & 4.4 & .46 \\
\hline $15 \ldots \ldots \ldots$ & 232.0 & 189.0 & 9.7 & 7.9 & .81 \\
\hline $16 . . \ldots \ldots \ldots$ & 150.5 & 100.5 & 6.2 & 4.2 & .68 \\
\hline $17 \ldots \ldots \ldots \ldots$ & 237.0 & $120 . \overline{5}$ & 9.9 & 5.0 & .50 \\
\hline $18 . \quad \ldots \ldots \ldots \ldots$ & 234.5 & 145.5 & 9.7 & 6.1 & .63 \\
\hline $19 \ldots \ldots \ldots \ldots$ & 112.0 & 103.5 & $4 f$ & 4.3 & .93 \\
\hline $20 \ldots \ldots \ldots \ldots$ & 173.5 & 81.0 & 7.2 & $\mathbf{3 . 4}$ & .47 \\
\hline $21 \ldots \ldots \ldots \ldots \ldots$ & 190.5 & 124.0 & 7.9 & 5.2 & .66 \\
\hline $22 \ldots \ldots \ldots$ & 273.0 & 180.5 & 11.4 & 7.5 & .66 \\
\hline $23 \ldots \ldots \ldots \ldots \ldots$ & 334.0 & 120.0 & 13.9 & 5.0 & .36 \\
\hline $24 \ldots \ldots \ldots \ldots$ & 213.5 & 123.5 & 8.9 & 5.1 & .57 \\
\hline $25 \ldots \ldots \ldots \ldots \ldots$ & 217.0 & 157.5 & 9.0 & 6.6 & .73 \\
\hline $\mathbf{2 6} \ldots \ldots \ldots \ldots$ & 167.5 & 162.5 & 7.0 & 68 & .97 \\
\hline $2 \pi \ldots \ldots \ldots \ldots$ & $18 \overline{5} .5$ & 112.0 & 7.7 & 4.7 & .61 \\
\hline & 325.0 & 138.0 & 13.5 & 5.7 & .42 \\
\hline $29 \ldots \ldots \ldots \ldots$ & 182.0 & 173.5 & 7.6 & 7.2 & .95 \\
\hline & 203.0 & 218.0 & 8.5 & 8.1 & 1.07 \\
\hline $31 \ldots . \quad . \ldots \ldots$ & 168.5 & 128.0 & 7.0 & 5.3 & .76 \\
\hline $32 \ldots \ldots \ldots \ldots \ldots$ & 205.5 & 115.5 & 8.5 & 48 & .56 \\
\hline $33 . \cdots \ldots$ & 169.0 & 114.5 & 7.0 & 4.8 & .69 \\
\hline Total ...... & 6322.0 & 4370.0 & & & \\
\hline A verage.... & 191.0 & 132.0 & & & \\
\hline
\end{tabular}


Table IV shows the deviations for each of the thirty-three observers. In the second and third columns are given the gross total amounts of deviation from the average judgment for each individual for all the twenty-four samples as placed by that individual on the Ayres and Thorndike scales, re spectively. The fourth and fifth columns give the average deviations for each individual. Comparing the figures in these two columns we see that in only two cuses is the average deviation on the Thorndike greater than on the Ayres, namely, for Obs. 9 and Obs. 30, where we have a difference in favor of the Ayres of .8 and .6, respectively. In the case of Obs. .5, the cieviations are practically equal, being 6.1 on each scale, and if there is any difference, it is in favor of the Thorndike by 2 points in the gross deviation. For all the other thirty observers we have a less amount of deriation on the Thorndike than on the Ayres scale.

We see, then, that this tendency toward greater miformity on the Thorndike scale is distributed pretty evenly over all the observers. The greater uniformity on the Thorndike scale has not been obtained hy some remarkable agreement of a few observers, but rather by a general tendency in that direction by all the observers.

V. Judgments on 273 Samples. A more exteusive study than the above was undertaken with 273 samples of handwriting collected from the eight grades of an ordinary grade school. In this case the samples were judged by only two individuals-a teacher of one of the grades of the school in question and the writer himself. The data were handled ex. actly as in the previous case with the thirty-three observers. The average of the two judgments for each of the 273 samples was taken, was put equal to 50 and the two judgments raised to this basis. In every case the deviations of the two observers were the same-an equal amount above in the one case and below in the other. For example, Obs. 1 graded Sample 21 on the Ayres scale 40, and Obs. 2 graded the same sample 35. The average grade for the two observers was therefore 37.5. Raised to the basis of 50 , the grades of Obs. 1 and Obs. 2 be come 53.5 and 46.5, respectively, giving in the one case a deviation of +3.5 and in the other -3.5 . The same thing will, of 


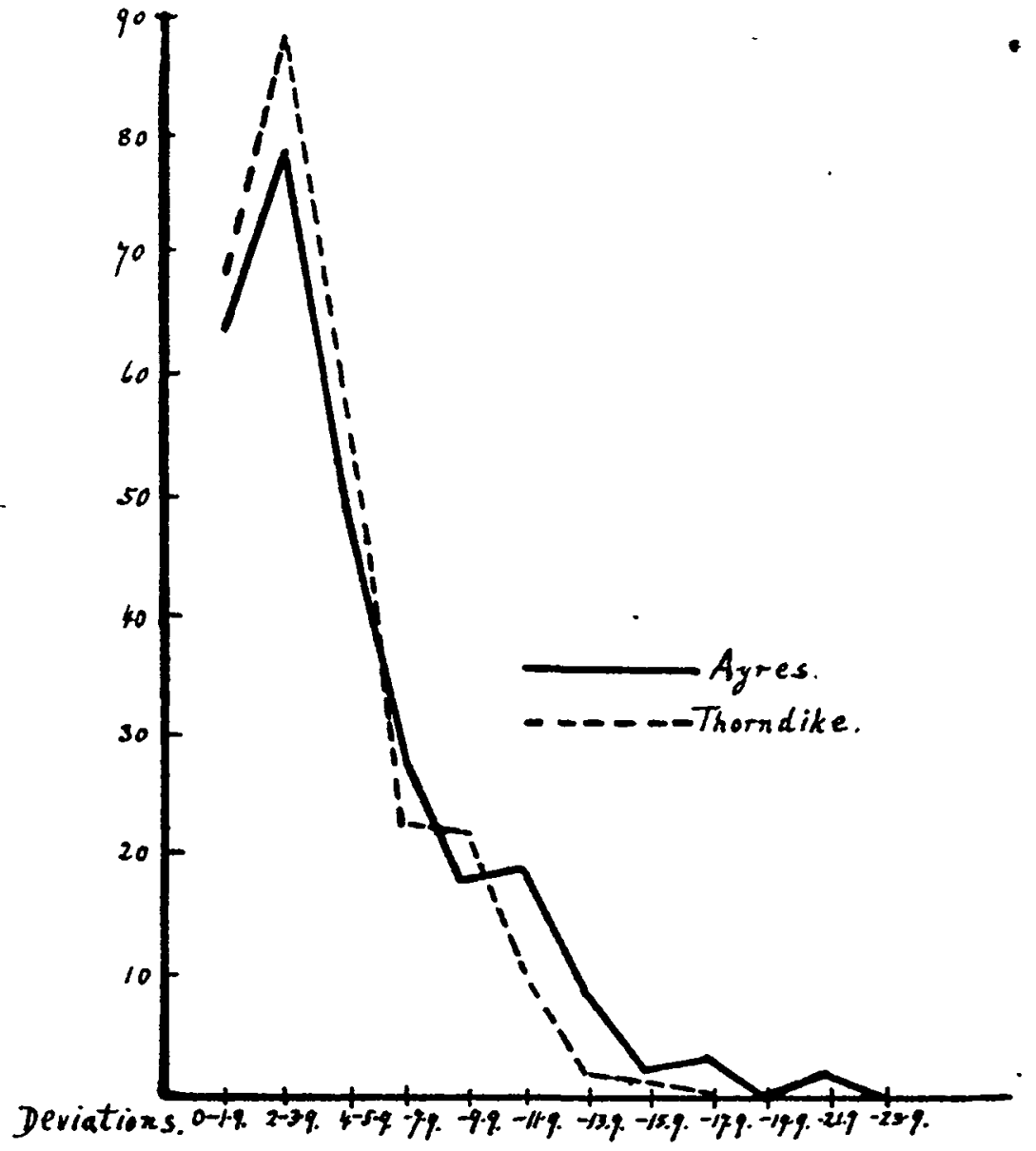


course, happen with every sample. Since the plus and minus signs are not significant for our present purpose, the deviation for each observer is the same.

The curves in Fig. 1 show the distribution of the 273 deviations for each scale. The vertical axis marks the number of deviations in each case, and along the horizontal axis the deviations have been assembled in equal steps, $i$. e., those lying between 0 and 1.99, the smallest deviations, then those between 2 and 3.99, and so on. It will be seen that the deviations are considerably more scattered on the Ayres than on the Thorndike scale. The great majority of the deviations on the Thorndike scale lie between 0 and 9.99 , whereas on the Ayres the curve does not ultimately descend until it has passed the 11.99 deviation point. The number of small deviations, i. e., between 0 and 1.99, on the Thorndike is 69, and on the Ayres 64. There are 89 deviations between 2 and 3.99 on the Thorndike and only 79 between the same points on the Ayres. In both cases the actual number of zero deviations is interesting. They indicate the number of times that the observers graded the sam. ples identically. On the Thorndike scale this occurred 60 times, on the Ayres 48 times, a difference of 12 times in favor of the Thorndike scale. The total deviation for each observer was, on the Ayres scale, 1254, and on the Thorndike, 987, a difference of 267 in favor of the Thomdike scale. The average deviation for the 273 samples was, on the Ayres, 4.6, and on the Thorndike, 3.6, a difference of one point in favor of the Thorndike, which is by no means a negligible quantity when we remember that 546 judgments were made by each observer.

With regard to the personal peculiarities of the two observers, it is interesting to note that Obs. 1 marked bigher than Obs. 2 on the Ayres and Obs. 2 marked higher than Obs. 1 on the Thorndike. On the former scale Obs. 1 graded 145 of the 273 samples higher than Obs. 2, whereas the later graded 150 samples higher on the Thorndike. In spite of these personal peculiarities in marking, it would seem that the general kigher grading of Obs. 2 on the Thorndike did not deviate so much from the average, as did the in general higher grading of Obs. 2 on the Ayres. 
VI. Summary. In conclusion, it may be said that the results of the intensive study with 24 samples as well as the more extensive one with 273 samples go to show that the unavoidable deviations of individual judgments in the use of the two scales in question are much smaller on the Thorndike than on the Ayres scale. The Thorndike scale shows a greater degree of reliability, a greater uniformity in results. I believe this is due to the fact that it has taken into account all those factors that go to influence our judgment of handwriting, and does not depend upon legibility alone. The factor of legibility is undoubtedly the most important factor, but I believe we cannot, in judging handwriting, abstract from all the other factors and pay attention to it alone, at least not when we are judging handwriting by means of such handwriting scales.

Lastly, if there was any partiality in regard to any one of the two scales, it undoubtedly lay in most observers in the direction of the Ayres scale. In spite of this, the Thorndike shows the greater uniformity in judgment. The preference shown to the Ayres is due to the convenient form of the scale and to the percentage system of marking the steps. I certainly believe that the Thorndike scale could be made much more convenient for the user if the samples were placed horizontally instead of vertically, as at present, and the different steps more clearly marked off from each other. Whether the percentage system of marking the steps should be adopted or not is not of greàt moment, although we must bear in mind that the average teacher is more familiar with this method of grading than with any other. 